\title{
Intratumoral injection of BCNU in ethanol (DTI-015) results in enhanced delivery to tumor - a pharmacokinetic study
}

\author{
Daniel A. Hamstra ${ }^{2,5}$, Bradford A. Moffat ${ }^{1,5}$, Daniel E. Hall ${ }^{1,5}$, John M. Young ${ }^{7}$, Timothy J. Desmond ${ }^{6}$, \\ Julie Carter ${ }^{7}$, Dennis Pietronigro ${ }^{7}$, Kirk A. Frey ${ }^{1,4,6}$, Alnawaz Rehemtulla ${ }^{1,2,5}$ and Brian D. Ross ${ }^{1,3,5}$ \\ The ${ }^{1}$ Departments of Radiology; ${ }^{2}$ Radiation Oncology; ${ }^{3}$ Biological Chemistry; ${ }^{4}$ Neurology; The ${ }^{5}$ Center for Molecular \\ Imaging; ${ }^{6}$ The Mental Health Research Institute, The University of Michigan Medical Center, Ann Arbor, MI; ${ }^{7}$ Direct \\ Therapeutics Inc. Redwood City, CA, USA
}

Key words: animal model, BCNU, brain tumor, MRI, pharmacokinetics

\begin{abstract}
Summary
Solvent facilitated perfusion (SFP) has been proposed as a technique to increase the delivery of chemotherapeutic agents to tumors. SFP entails direct injection of the agent into the tumor in a water-miscible organic solvent, and because the solvent moves easily through both aqueous solutions and cellular membranes it drives the penetration of the solubilized anticancer agent throughout the tumor. To test this hypothesis, we compared the pharmacokinetics (PK) of ${ }^{14} \mathrm{C}$-labeled 1,3-bis-chlorethyl-1-nitrosourea (BCNU) in intra-cerebral 9L rat gliomas after intravenous (IV) infusion in $90 \%$ saline $-10 \%$ ethanol or direct intratumoral (IT) injection of ${ }^{14} \mathrm{C}$-BCNU in $100 \%$ ethanol (DTI-015). Treatment with DTI-015 yielded a peak radioactive count (Cmax) for the ${ }^{14} \mathrm{C}$ label that was $100-1000$ fold higher in the tumor than in all other tissues in addition to a concentration in the tumor that was 100-fold higher than that achieved following IV infusion of ${ }^{14} \mathrm{C}$-BCNU. Pathologic and auto-radiographic analysis of tissue sections following IT injection of ${ }^{14} \mathrm{C}-\mathrm{BCNU}$ in ethanol into either tumor or normal rat brain revealed both an enhanced local volume of distribution and an increased concentration of BCNU delivered to tumor compared to non-tumor bearing brain. To investigate the mechanism behind the SFP of BCNU to the tumor both dynamic contrast and perfusion MRI were performed on 9L tumors before and after treatment and demonstrated a decrease in tumor perfusion following IT injection of DTI-015. Finally, initial PK of patient blood samples following administration of DTI-015 into relapsed high-grade glioma indicated a 20-fold decrease in systemic exposure to BCNU compared to IV infusion of BCNU providing further evidence for the enhanced therapeutic ratio observed for DTI-015.
\end{abstract}

Abbreviations: AUC - area under the concentration-time curve; BCNU - 1,3-bis-chlorethyl-1-nitrosourea; CED convection enhanced delivery; Cmax - peak concentration; CPM - counts per minute; DTI- 015 - BCNU prepared in $100 \%$ ethanol; IT - intratumoral; IV - intravenous; LD10 - the dose of drug which results in death of $10 \%$ of the animals due to drug toxicity; MRI - magnetic resonance imaging; PK - pharmacokinetics; SEM - standard error of the mean; SFP - solvent facilitated perfusion; $t_{1 / 2}$ - half-life; TTR - tumor-to-tissue ratio

\section{Introduction}

High-grade malignant glioma carries a grave prognosis with median survival typically less than 12 months from diagnosis even with aggressive treatment. The typical management strategy entails maximal surgical resection followed by post-operative radiotherapy [1]. Intravenously administered BCNU has been the leading chemotherapeutic agent for treating this patient population for decades; however, despite activity against glioma cells both in culture and in animal models there is limited clinical efficacy which has prompted numerous investigations into ways to enhance the pharmacokinetics (PK) of this agent [2]. The limited efficacy of adjuvant chemotherapy for high-grade gliomas was highlighted in a recent meta-analysis which indicated only a $6 \%$ increase in median survival in patients treated with adjuvant chemotherapy (typically BCNU) following maximal surgical resection and/or radiation therapy [3].

Attempts to increase this response through dose escalation of BCNU administered systemically have been hampered by acute toxicity to bone marrow and gastrointestinal tract and delayed toxicity to liver and lungs [2,4-6]. Therefore, local/regional delivery of BCNU either through intra-arterial infusion [7,8] or through the use of BCNU impregnated wafers implanted in the resection cavity $\left(\right.$ Gliadel ${ }^{\circledR}$ ) have been attempted $[9,10]$. Unfortunately, neither of these techniques has offered a significant advantage over traditional IV infusion of BCNU. Intra-arterial infusion resulted in a less than 4-fold increase in tumor-to-tissue ratio (TTR) and was complicated by unacceptable optic and neurologic toxicity $[11,12]$. Following the difficulty 
with local intra-arterial delivery attempts were made using BCNU contained within a sustained release formulation implanted directly into the resection cavity. Initial studies utilized relatively low dose wafers which gave only a modest increase in survival following treatment of recurrent or primary glioblastoma $[10,13]$. More recent studies have evaluated wafers containing increased concentrations of BCNU, but these eventually produced both local and systemic toxicity and the clinical benefit of these higher dose wafers has yet to be demonstrated [14]. In part, this limited efficacy may be due to the fact that Gliadel wafers are limited by bulk diffusion of $\mathrm{BCNU}$ from the implant to surrounding tissues, and are, therefore, only utilizable after maximal surgical resection and even then there is still limited entrance of drug into the surrounding tissues, which is typically not more than a few millimeters [15]. Due to the limited transit of drug direct intratumoral infusion of drugs in aqueous solutions (convection enhanced delivery, CED) has been investigated to increase delivery to the tumor while also enhancing the TTR [16]. However, this technique is limited by the long time required for infusion and by limited and heterogeneous distribution of the compounds within the tumor [17]. Despite this fact CED is being actively pursued both in preclinical models [18] and in clinical investigation for patients with high-grade glioma [19].

Solvent facilitated perfusion (SFP) is another new treatment technique which has been proposed to achieve an enhanced TTR for chemotherapeutic agents. This method utilizes a water-miscible organic solvent that can move freely though both aqueous solutions and cell membranes thus facilitating transit of the chemotherapeutic agent some distance from the tumor. BCNU suspended in $100 \%$ ethanol (herein termed DTI-015) is the first drug : solvent system to be used to study this SFP model. It has been evaluated both in animal models and in patients with recurrent high-grade glioma and in both cases DTI-015 was demonstrated to have significant anti-tumor activity [20,21]. In one preclinical model, treatment of rats bearing T9 gliosarcomas with DTI-015 resulted in a $>400 \%$ increase in life-span with $40 \%$ of animals cured of their tumors [21]. In a separate study, diffusion-weighted MRI was performed following the injection of DTI-015 into established 9L gliosarcomas and revealed a rapid and substantial increase in the apparent diffusion coefficient (ADC), which is a radiologic measure of cell death [22], followed by significant regression of the tumor mass with $75 \%$ of animals free of tumor by MRI and pathologic analysis at 30 days [23]. More importantly, changes in ADC were witnessed throughout the tumor despite the fact that the volume of DTI-015 injected was at most $50 \%$ of the tumor volume. These diffuse changes in ADC throughout the injected tumors were thus an indirect suggestion of SFP of drug to the entire tumor mass. Finally, a recent phase I/II trial was reported on 40 heavily pretreated patients with inoperable recurrences of primary brain tumors $(90 \%$ of which were WHO grade III or IV), $58 \%$ of whom had been previously treated with nitrosoureas. Despite this previously treated population there was a significant benefit in patients treated with less than or equal to the maximal tolerated dose of DTI-015 (240 $\mathrm{mg}$ and $5 \mathrm{ml}$ ) where the median survival was 55 weeks in patients with recurrent, inoperable GBM, as compared to a historical control of 25 weeks [20].

Despite these preclinical and clinical data the local and systemic PK of BCNU following injection of DTI015 into intra-cerebral tumors in either experimental animals or clinical samples has not been reported. We, therefore, evaluated the distribution of radioactivity following IT or IV injection of ${ }^{14} \mathrm{C}-\mathrm{BCNU}$ in Fischer 344 rats bearing established 9L gliosarcomas, and utilized MRI measures of tumor perfusion to more fully evaluate the PK of DTI-015 administration. Finally, the initial pilot experience with the systemic PK of BCNU following IT treatment with DTI-015 in patients with recurrent gliomas is reported.

\section{Materials and methods}

\section{Cell culture}

Rat 9L brain tumor cells (passage 12) were obtained from the Brain Tumor Research Center at the University of California at San Francisco. The cells were grown as monolayers in $175 \mathrm{~cm}^{2}$ sterile plastic flasks in Eagle's MEM with $10 \%$ fetal bovine serum. Cells were cultured at $37{ }^{\circ} \mathrm{C}$ in an atmosphere containing $95 / 5 \%$ air $/ \mathrm{CO}_{2}$ until confluent, and were harvested by trypsinization, counted, and resuspended in serum-free medium for injection. The 9L cells were carried only until passage number 40 at which time cells were reactivated from frozen stocks.

\section{Animals}

Male Fischer 344 (F344/NHsd) rats were obtained from Harlan Sprague Dawley (Indianapolis, IN) and were acclimated in house, 2 per cage with food and water ad libitum for at least 1 week prior to experimentation. Animals weighing 125-150 were used for tumor cell implantation and subsequent treatment with DTI-015 or for injection of DTI-015 into the normal brain of nontumor bearing mice.

\section{Preparation of ${ }^{14} C-B C N U$}

${ }^{14} \mathrm{C}$-[carbonyl]-1,3-bischlorethyl-1-nitrosourea (specific activity $53 \mathrm{mCi} / \mathrm{mol})$ or 1,3 -bis(2-chlorethyl- $\left.\left[2-{ }^{14} \mathrm{C}\right]\right)$ 1-nitrosourea (specific activity $205 \mathrm{mCi} / \mathrm{mol}$ ) were obtained from Moravek Biochemicals Inc (Brea, CA) as a dry solid packaged under argon. The materials were reconstituted in ethanol containing unlabeled $\mathrm{BCNU}$ at a concentration of $67 \mathrm{mg} / \mathrm{ml}$ to give the DTI-015 formulation.

For experiments evaluating the distribution of ${ }^{14} \mathrm{C}$ labeled BCNU within tumor or normal brain slices the compound with ${ }^{14} \mathrm{C}$ in the carbonyl position was utilized where a total of $15 \mu \mathrm{l}$ of DTI-015 was injected containing $1 \mathrm{mg}$ of unlabeled $\mathrm{BCNU}$ and $135 \mathrm{nCi}$. In all other PK experiments, the compound with ${ }^{14} \mathrm{C}$ in the 
ethyl position was utilized with a total of $15 \mu$ l of DTI015 injected containing $1 \mathrm{mg}$ of unlabeled $\mathrm{BCNU}$ and $1 \mu \mathrm{Ci}$. For intravenous administration the 1,3-bis(2chlorethyl-[2- $\left.{ }^{14} \mathrm{C}\right]$ )-1-nitrosourea compound was reconstituted in ethanol containing unlabeled BCNU and further diluted in saline to a concentration of $1 \mathrm{mg}$ BCNU (containing $1 \mu \mathrm{Ci}$ ) per $900 \mu \mathrm{l}$ ethanol/saline $(10 \% / 90 \%)$.

\section{Induction of brain tumors}

Intra-cerebral tumor implantation was performed as previously described (24). Male Fischer 344 rats weighing between 125 and $150 \mathrm{~g}$ were anesthetized with a ketamine/xylazine mixture administered intraperitoneally. A small skin incision was made over the right hemisphere, and a $1 \mathrm{~cm}$ diameter burr hole was drilled through the skull using a high speed drill. Tumor cells $\left(10^{5}\right)$ contained in a volume of $5 \mu \mathrm{l}$ were injected into the right forebrain at a depth of $3 \mathrm{~mm}$ via a Hamilton syringe equipped with a 30 gauge needle. The area was rinsed with $70 \%$ ethanol, and the burr hole was filled with bone wax to minimize extra-cerebral extension of the tumor. The skin incision was closed with sutures, and the rats were allowed to recover from anesthesia before being returned to the animal quarters.

\section{Magnetic resonance imaging}

All in vivo MR experiments were performed on a Varian NMR Instruments system equipped with a $7.0 \mathrm{~T}$ (300 MHz proton frequency), $18.3-\mathrm{cm}$ horizontal bore magnet. For MRI examination rats were anesthetized with $1.5 \%$ isoflurane and maintained at $37{ }^{\circ} \mathrm{C}$ inside the magnet using a heated circulating water blanket. MRI of rat brains were initiated between 8 and 11 days after cell implantation and repeated approximately every 2 days using a 32-mm-diameter quadrature radio frequency head coil (USA Instruments, Highland Heights, OH). Multislice axial $T_{2}$ weighted images (FOV $=30 \times 30 \mathrm{~mm}$ and image matrix $=128 \times 128)$ were acquired by using a fastspin echo (FSE) sequence $\left(\mathrm{TR} / \mathrm{TE}_{\mathrm{eff}}=4000 / 45 \mathrm{~ms}\right.$, $\mathrm{ETL}=8$, Thk $=1 \mathrm{~mm}$ ). The tumor boundary visualized in each slice was electronically outlined by using image processing software $\left(\mathrm{MATLAB}^{\circledR}\right)$ for calculation of tumor volume. For quantification of contrast agent uptake $T_{1}$ weighted spin echo MRI was performed pre- and post intra-peritoneal injection of GdDTPA $\left(1.0 \mathrm{ml}\right.$ of $20 \%$ Magnevist $\left.^{\circledR}\right)$. TR/TE $=1000 / 15 \mathrm{~ms}$, thk $=1 \mathrm{~mm}, \mathrm{FOV}=30 \times 30 \mathrm{~mm}$ and image matrix $=$ $128 \times 128$. For blood flow imaging, continuous arterial spin labeling (CASL) MRI was performed with a FSE based imaging sequence. Briefly a 3 second train of hyperbolic inversion pulses was used to invert the signal arising from inflowing blood, immediately before the initial $90^{\circ}$ pulse of a 16 -echo, 128-phase FSE sequence (TR/TE $\mathrm{Tff}_{\text {ef }}$ of $400 / 14 \mathrm{~ms}, 2 \mathrm{~mm}$ slice thickness and 8 transients). The images were acquired with a field $3 \times 3$ $\mathrm{cm}$ field of view and the $128 \times 128$ acquisition matrix was subsequently zero-filled to $256 \times 256$. A $T_{1}$ map of the imaged slice was also acquired with a magnetization inversion-prepared 16-echo, 64-phase encoding FSE sequence. Five different inversion times, $T_{i}$, were used with 2 transients and TR/TE eff $_{\text {of }} 10,000 / 14 \mathrm{~ms}$. Perfusion images or TBF maps were calculated using the formula for continuous labeling.

$$
\mathrm{TBF}=\frac{\lambda}{T_{1}} \frac{\left(S_{0}-S_{1}\right)}{2 \alpha S_{0}}
$$

where $\lambda$ is the blood/tissue partition function (assumed to be 0.9 ), $T_{1}$ is the tissue longitudinal relaxation time, $S_{0}$ and $S_{1}$ are the image signals with inversion pulses applied to control and tag zones respectively, and $\alpha$ is the efficiency of the inversion pulses. All MRI acquisition matrices were zero filled to $256 \times 256$ so that the resulting image dimensions were identical.

\section{Stereotactic injections of DTI-015}

When tumors had reached a mean volume of $65 \pm 7.5 \mu \mathrm{l}$ rats were anesthetized with $0.1-0.2 \mathrm{ml}$ ketamine $\mathrm{HCl}(100 \mathrm{mg} / \mathrm{ml})$ intramuscularly and placed in the stereotactic device (David Kopf Instruments, Tujunga, CA) with the bite bar set at $-2.4 \mathrm{~mm}$. The scalp was opened with a scalpel and the skull was cleaned of tissue to locate the original burr hole made for tumor cell injection. The injection needle made from 30 gauge stainless steel tubing (HTX-30, Small Parts Inc, Miami Lakes, FL) attached to PE-10 polyethylene tubing (Clay Adams, Parsippany, NJ) was placed in the hole just touching the surface of the brain and the scale was read. From this point the needle was introduced into the tumor a distance approximately the total depth of the tumor and then retracted to the midpoint of the tumor (as determined by diagrams of MR images obtained 2 days previously). Using a Harvard Pump 11 and a $50 \mu \mathrm{l}$ Hamilton syringe, $15 \mu \mathrm{l}$ of $\left[{ }^{14} \mathrm{C}\right]-\mathrm{BCNU}$ was infused over $2 \mathrm{~m}$ in at a rate of $7.5 \mu \mathrm{l} / \mathrm{min}$. The needle was left in place an additional $30 \mathrm{~s}$ to promote diffusion of the injection into the tumor and to prevent the drawing of $\left[{ }^{14} \mathrm{C}\right]-\mathrm{BCNU}$ along the needle track upon withdrawal. For injections into normal brains of non-tumor bearing animals, injections were made $3 \mathrm{~mm}$ below the dura.

\section{Animal termination}

Representative animals from each group were killed by decapitation at the indicated times post injection and the brains were quickly removed. For experiments requiring sectioning they were immediately mounted in anticipation of coronal tissue sectioning (see below). In separate experiments for kinetic data analysis a blood sample was obtained prior to euthanasia. Once the animal had been harvested the brains were removed and the tumors teased out in its entirety and transferred to an appropriate vial. Small slabs of ipsilateral (adjacent to the tumor) and contralateral cortex were subsequently taken. An incision was made in the abdomen past the sternum and small samples of the following tissues were taken (in the following order): lung, liver, kidney (left), spleen, bone marrow (right femur), and testis (left). 


\section{Frozen sections}

Upon sacrifice, the forebrain was cut from the hindbrain and mounted on a small piece of gauze saturated with M-1 embedding medium (Shandon-Lipshaw, Pittsburg, PA) on a glass slide oriented for coronal sectioning. This was then frozen with crushed dry ice and coated with M-1 before storing at $-80{ }^{\circ} \mathrm{C}$. The tissue gauze was thawed from the slide and mounted on a chuck with additional M-1 and surrounded by crushed dry ice to freeze the media. The tissue was then placed in the cryostat (Hacker Instruments, Fairfield, NJ) and allowed to equilibrate to chamber temperature before sectioning. Serial sections through the tumor were collected beginning prior to the tumor and ending just after the tumor disappeared from the tissue. Serial $20 \mu \mathrm{m}$ sections were cut, placed on slides (three sections per slide), and high temperature thaw mounted to prevent diffusion of the label and completely dry the sections. Slides were placed in X0ray cassettes with radioactive standards and opposed to Hyperfil $\beta$-max (Amersham, Arlington Heights, IL) for 6 days. Films were developed in D-19 (Kodak, Rochester, NY) for $4 \mathrm{~min}$, transferred to $1 \%$ acetic acid stop bath for $30 \mathrm{~s}$ and fixed with Rapid Fixer (Kodak) for 5 min. The films were washed in running tap water for $20 \mathrm{~min}$, rinsed in distilled water, and air dried.

\section{Brain radiolabel densitometry}

Auto radiograms were analyzed using imaging software (Imaging Research Inc, St. Catherines, Ontario, Canada). Scanning coordinates on selected slides were arbitrarily chosen to be representative and the autoradiographs were scanned with s Sony XC-77 CCD camera. The data were captured using MCID M5+ system with a Matrox Genesis imaging board and saved in the software format (*IM) for analysis and in *.TIF format for reproduction. Film density was converted to local tissue ${ }^{14} \mathrm{C}$ concentration $(\mathrm{nCi} / \mathrm{g}$ tissue) based upon the internal standards, and the local molar concentration $(\mathrm{mM})$ were based upon the injected BCNU specific activity of $28.9 \mu \mathrm{Ci} / \mathrm{mmol}$. Tumor and section volumes were determined with the same system.

\section{Histopathological evaluation of brain tissue sections}

Following autoradiography, selected slides representative of the site of injection of DTI-015 into the tumors and into the brains of normal animals were stained with hematoxylin and eosin and submitted to Dr. Mark T. Butt (Pathology Associates International, Frederick, MD) for independent histopathological evaluation.

Radioactivity determinations in peripheral blood, tumor samples and tissue samples

At the time of sacrifice of each animal the representative tissues were harvested as indicated above and stored at $-70{ }^{\circ} \mathrm{C}$. Portions of these frozen samples (approximately $50 \mathrm{mg}$ for blood and $100 \mathrm{mg}$ for tissues) were accurately weighed and digested in $0.5 \mathrm{ml}$ of 'Solvable' (NEF910, NEN Research Products, Boston, MA) at room temperature for $48 \mathrm{~h}$. The tissue digests were decolorized with $0.25 \mathrm{ml}$ of $30 \% \mathrm{H}_{2} \mathrm{O}_{2}$ (Sigma Chemicals, St. Louis, MO), $12 \mathrm{ml}$ of Cytoscint ES (ICN Biochemicals, Costa Mesa, CA) were added, and the samples were counted for $1 \mathrm{~min}$. No quenching was observed in non-radioactive tissue samples spiked with a known amount of radioactivity and subjected to the same procedures. For each series of samples a background count was obtained for 10 blank samples counted simultaneously which was then averaged and subtracted from each sample's count.

\section{Human blood BCNU analysis}

Three patients enrolled in an IRB approved prospective trial of DTI-015 for recurrent high-grade glioma were treated at Evanston Hospital (Evanston, IL, 2 patients) or The University of Southern California Medical Center (Los Angeles, CA, 1 patient) between 11/13/01 and $7 / 12 / 02$. Patients were treated per the protocol previously described (20). Seven serial blood samples were collected between 5 and $360 \mathrm{~min}$ following injection of DTI-015. Although the exact timing of each phlebotomy was dependent upon the unique clinical characteristics of the case each patient did have blood draws that spanned at least a 120 min time period. For the first two patients blood samples were immediately extracted with ethyl-acetate and then frozen before analysis. In the third patient blood samples were first frozen and then extracted with ethyl-acetate at the analytic laboratory.

\section{Statistical and pharmacokinetic calculations}

Data for radioactivity in tissues was expressed as the mean \pm standard error of the mean $($ SEM $=$ standard deviation/square-root $(n-1))$. The SEM for ratios was calculated using the following formula:

$$
\begin{aligned}
\operatorname{SEM} \mathrm{A} / \mathrm{B}= & (\text { SEM A } / \text { mean } \mathrm{A}) \\
& +(\text { SEM B } / \text { mean } \mathrm{B})
\end{aligned}
$$

All statistical comparisons between groups were done using Microsoft Excel with the Student's $t$-test (twotailed with unequal variance) except in the comparison between counts in tumor following direct IT injection or IV where a single-tailed probability function was utilized given the hypothesis that IT injection would result in increased delivery of drug to tumors. Pharmacokinetic calculations were performed using 'PK Functions for Microsoft Excel', a series of Add-in functions for Excel spreadsheets, designed and written by Joel I. Usansky, Atul Desai, and Diane Tang-Liu, Department of Pharmacokinetics and Drug Metabolism, Allergan, Irvine, CA. 


\section{Results}

Injection of DTI-015 intratumorally results in increased exposure of tumor to BCNU as compared to all other tissues

In order to assess the pharmacokinetics of bis-[2-chlorethyl-2- ${ }^{14} \mathrm{C}$ ]-nitrosourea intra-cerebral 9L tumors were established in Fischer 344 rats. Tumor growth was followed by serial MRI scans (Figure 1) where approximately 12-14 days after implantation $T_{1}$ weighted MRI pre-contrast injection revealed a large, isointense mass in the right cerebral hemisphere with mild compressive effect upon surrounding cerebral tissues. Following IP injection of GdDTPA the tumors were briskly and uniformly enhancing consistent with their high-grade pathology. Once tumors had reached a mean volume of $65 \mu \mathrm{l}$ the rats were sterotactically injected with $15 \mu \mathrm{l}$ of ${ }^{14} \mathrm{C}$-labeled $\mathrm{BCNU}$ with injection guided by coordinates obtained from MRI scans performed the day prior to injection to assure that it occurred at the appropriate location and depth within the central mass of the tumor. Groups of 5 animals were sacrificed 1, 15, 60, 360, 1440, and $4320 \mathrm{~min}$ after injection (except for the 360 min time point which only contained 3 animals), and radioactivity was counted in each tissue and expressed as counts per minute per mg of tissue (CPM/mg tissue). BCNU exerts its biologic effect through both carbamoylation (a short-lived and reversible phenomenon) and alkylation (a long-lived and irreversible phenomenon) [25]. Due to the presence of the radiolabel in both alkyl groups of bis-[2-chlorethyl-2- $\left.{ }^{14} \mathrm{C}\right]$-nitrosourea, carbamylation and alkylation are indistinguishable in this study, and no attempt was made to quantify either these two or other products of BCNU.

As can be seen in Figure 2a there was a rapid rise in ${ }^{14} \mathrm{C}$ label detected in all tissues reaching a peak (Cmax) in 15 min or less except for the blood and kidneys which did not achieve Cmax until the $1 \mathrm{~h}$ time point. Not surprisingly the time to Cmax was shorter in intracerebral tissues (which were adjacent to the direct injection of ${ }^{14} \mathrm{C}$-BCNU) where Cmax was typically seen at the $1 \mathrm{~min}$ post-injection time point as opposed to systemic tissues where this peak was usually at either 15 or $60 \mathrm{~min}$. In all cases, following the initial peak radioactivity there was an initial shorter half-life $\left(t_{1 / 2}\right)$ over the first $3 \mathrm{~h}$ (Figure $2 \mathrm{a}$ ) followed by a longer terminal half-life from 24 to $72 \mathrm{~h}$ (Figure $2 \mathrm{~b}$ and Table 1). The half-life during the initial phase (up to $3 \mathrm{~h}$ after injection) was much greater in systemic tissues (except for kidney and lung) with an average of $12.6 \pm 6.9 \mathrm{~h}$ when compared to tumor and brain tissues, which had half-lives between 1.8 and $2.4 \mathrm{~h}$. This difference in initial $t_{1 / 2}$ is consistent with the rapid redistribution of $\mathrm{BCNU}$ and metabolites from within the intra cerebral compartment to other systemic tissues during the early period after injection. The shorter half-life of radioactivity within the kidney likely reflects the well-documented renal excretion of BCNU and its metabolites; while the short half-life in the lung may reflect the fact that up to $10 \%$ of the alkyl portion of BCNU is expired as $\mathrm{CO}_{2}$ within the first $24 \mathrm{~h}$ after treatment [26].

The initial fast fall in radioactivity observed during the first $3 \mathrm{~h}$ was followed by a more prolonged clearance in the period from 24 to 72 hours (Figure $2 \mathrm{~b}$ and Table 1) with a half-life in the tumor of greater than $72 \mathrm{~h}$ and that in all other tissues markedly shorter $(41 \pm 6.9 \mathrm{~h})$. The main exception to this was the blood where the terminal half-life of $68 \mathrm{~h}$ was much closer to that seen for the tumor and may reflect the late slow release of ${ }^{14} \mathrm{C}$-BCNU and metabolites from the tumor into the systemic circulation.

In addition to a prolonged half-life for ${ }^{14} \mathrm{C}$-label, it is also clear from this first set of experiments that ${ }^{14} \mathrm{C}$ exposure to the tumor is much greater than that observed for all other tissues both in terms of maximum concentration achieved (Cmax, $P<0.0005)$ and in terms of net exposure over the $72 \mathrm{~h}$ experiment, as expressed as the area under the concentration vs. time curve (AUC, $P<0.014$ ) (Table 1). In fact, the maximal concentration achieved in the tumor as compared to all other noncerebral tissues ranged between 100- and 2000- fold higher giving a very high tumor-to-tissue ratio for Cmax (TTR Cmax). In comparison, the ipsilateral brain was exposed to a maximal concentration of ${ }^{14} \mathrm{C}$-labled BCNU which although significantly higher than most other tissues (Cmax 176.0 vs. 14.1 CPM/mg tissue) was still 40-
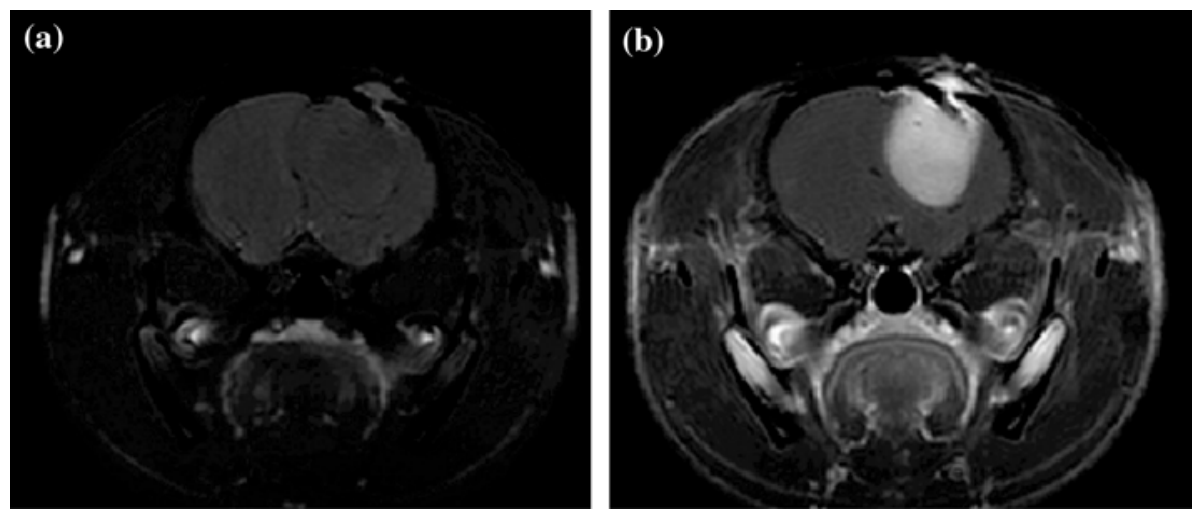

Figure 1. Intra-cerebral 9L gliosarcoma model. $T_{1}$-weight MRI images were obtained of tumor bearing animals both pre- (a) and 20 min post-IP administration of GdDTPA (b). 

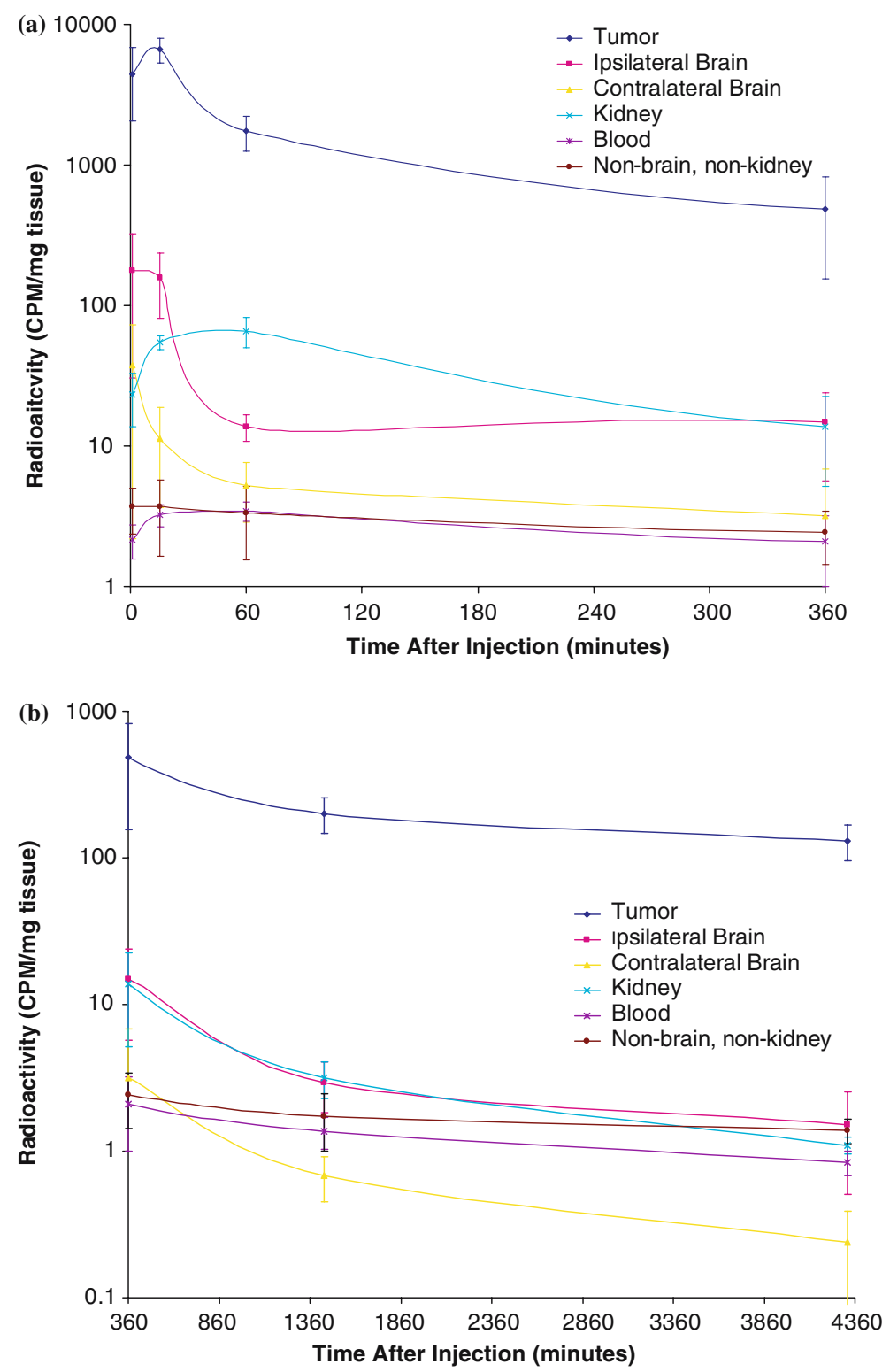

Figure 2. Time dependent distribution of radioactivity following IT delivery of ${ }^{14} \mathrm{C}$-labeled DTI-015 in the 9L intra-cerebral gliosarcoma model. Fischer 344 rats bearing $9 \mathrm{~L}$ gliosarcomas were treated with a $15 \mu \mathrm{l}$ injection of 1,3 -bis(2-chlorethyl-[2- $\left.\left.{ }^{14} \mathrm{C}\right]\right)$-1-nitrosourea $(1 \mathrm{mg}$ cold $\mathrm{BCNU}$, $1 \mu \mathrm{Ci}{ }^{14} \mathrm{C}$-label). Tumor, ipsilateral brain, contralateral brain, kidney, and blood levels are plotted individually. In addition, the average of all other non-cerebral tissues are also depicted. Data are plotted as radioactivity (CPM/mg tissue) as a function of time (min) since injection. Values represent the mean \pm SEM for 5 animals (except for the 360 min time point which only had 3 animals). Background for this experiment was 32.6 CPM. Note the different logarithmic scales on the $y$-axis. (a) Early data from the time of treatment to 360 minute after treatment. (b) Late data from $360 \mathrm{~min}$ after treatment to $4320 \mathrm{~min}(72 \mathrm{~h})$ after treatment.

fold less than the tumor. Further, by 60 min following injection the concentration in the ipsilateral brain was similar to other systemic tissues $\left(C_{60 \mathrm{~min}} 14.8\right.$ vs. 13.3 CPM $/ \mathrm{mg}$ tissue). The contralateral brain achieved a peak concentration (37.6 CPM/mg tissue) which was between that of most systemic tissues and the ispilateral brain, but was still $\sim 150$-fold less than that seen in the tumor. In addition, similar to that seen for the ipsilateral brain, by $60 \mathrm{~min}$ after injection there was a significant fall in the concentration of ${ }^{14} \mathrm{C}$-label in the contralateral brain such that it was similar to that for most systemic tissues (5.24 CPM/mg tissue) with only the kidneys and liver having higher activity at this time point.

Since BCNU exerts its activity by covalent modification of targets within the cell, peak concentrations of
${ }^{14} \mathrm{C}$-label may not be the best indicator of ultimate efficacy; rather, the total exposure to ${ }^{14} \mathrm{C}-\mathrm{BCNU}$ and its metabolites to the tissues of interest, as expressed as the area under the concentration vs. time curve (AUC, Table 1), may be a better PK parameter to monitor. The AUC of tumor, $1912\left(\mathrm{CPM} / \mathrm{mg}\right.$ tissue $/ \mathrm{min} \times 10^{-3}$ ) was 50-500 times greater than the AUC for all other tissues yielding a very high tumor-to-tissue ratio for AUC (TTR AUC). The kidneys, liver, and ipsilateral brain all had similar AUCs between 17 and 40 $\left(\mathrm{CPM} / \mathrm{mg}\right.$ tissue $\left./ \mathrm{min} \times 10^{-3}\right)$ which were 50 -100-fold less than the tumor. In contrast, the contralateral cerebral hemisphere was exposed to an AUC for ${ }^{14} \mathrm{C}$ label which was similar in nature to other systemic tissues (lung, spleen, blood, and testes) with AUC's 
Table 1. Pharmacokinetic parameters for DTI-015 injected intratumorally in established 9L intra-cerebral tumors in fischer 344 rats

\begin{tabular}{|c|c|c|c|c|c|c|c|c|c|c|}
\hline \multirow[b]{2}{*}{ Tumor } & \multicolumn{2}{|l|}{ Cmax } & \multicolumn{2}{|c|}{$\begin{array}{l}\text { Tumor to tissue } \\
\text { ratio for Cmax }\end{array}$} & \multicolumn{2}{|c|}{$\mathrm{AUC}_{\mathbf{0 - t}}\left(\times 10 \mathrm{e}^{-3}\right)$} & \multicolumn{2}{|c|}{$\begin{array}{l}\text { Tumor to tissue } \\
\text { ratio for AUC }\end{array}$} & \multirow{2}{*}{$\begin{array}{c}\mathrm{t}_{1 / 2}(\mathrm{~h}) \\
0-3 \mathrm{~h} \\
1.8\end{array}$} & \multirow{2}{*}{$\begin{array}{l}\mathrm{t}_{1 / 2(\mathrm{~h})} \\
24-72 \mathrm{~h} \\
77.7\end{array}$} \\
\hline & 6670.0 & (1347) & & & 1912 & $(516)$ & & & & \\
\hline Ipsilateral brain & 176.0 & $(146)$ & 38 & $(13.2)$ & 28.3 & $(4.0)$ & 67.6 & $(0.41)$ & 2.0 & 50.2 \\
\hline Contralateral brain & 37.6 & $(18)$ & 178 & (12.9) & 5.5 & (1.1) & 347 & $(0.47)$ & 2.4 & 32.0 \\
\hline Kidney & 65.9 & (16) & 101 & $(12.6)$ & 37.4 & (6.3) & 51.2 & $(0.44)$ & 3.8 & 31.5 \\
\hline Liver & 11.6 & (1.8) & 575 & $(12.5)$ & 17.9 & (3.5) & 107 & $(0.47)$ & 12.3 & 28.4 \\
\hline Lung & 6.8 & $(2.2)$ & 982 & $(12.7)$ & 7.5 & (1.4) & 254 & $(0.45)$ & 5.1 & 46.3 \\
\hline Spleen & 3.7 & $(1.2)$ & 1813 & $(12.7)$ & 5.8 & $(0.8)$ & 332 & $(0.40)$ & 27.0 & 28.2 \\
\hline Blood & 3.4 & $(0.54)$ & 1944 & $(12.5)$ & 6.2 & (1.1) & 308 & $(0.45)$ & 14.9 & 68.0 \\
\hline Testes & 2.7 & (1.0) & 2470 & (12.8) & 3.4 & $(0.5)$ & 568 & $(0.41)$ & 12.6 & 43.0 \\
\hline
\end{tabular}

Pharmacokinetic parameters for ${ }^{14} \mathrm{C}$-labeled BCNU following IT injection of BCNU (1 mg, $\left.1 \mu \mathrm{Ci}\right)$. Peak concentration $(\mathrm{Cmax})(\mathrm{CPM} / \mathrm{mg}$ tissue), Tumor-to-tissue ratio for Cmax (TTR Cmax), area under the curve (AUC) (CPM/mg tissue/min), and tumor-to-tissue ratio for AUC (TTR AUC) were all calculated. In addition, the half-life of the ${ }^{14} \mathrm{C}$ label in tissues either immediately following injection $\left(t_{1 / 2} 0-3 \mathrm{~h}\right)$ or of the late elimination $\left(t_{1 / 2} 24-72 \mathrm{~h}\right)$ were calculated. Values in each category represent the average of 5 animals ( \pm the standard error of the mean). Background for this experiment was $32.6 \mathrm{CPM}$.

between 3.4 and $7.5\left(\mathrm{CPM} / \mathrm{mg}\right.$ tissue $\left./ \mathrm{min} \times 10^{-3}\right)$ and TTR AUC's between 250 and 500 .

Finally, not only were the Cmax and AUC increased in tumor following injection these values may actually have underestimated the magnitude of the therapeutic ratio, for at the end of the $72 \mathrm{~h}$ experiment (Figure 2b) there was still a significant amount of radioactivity in the tumor $(131 \pm 71 \mathrm{CPM} / \mathrm{mg}$ tissue $)$. At this late time point, in contrast, there was only minimal residual radioactivity in all other tissues including: peripheral tissues (average for all extra cerebral tissues of $0.89 \pm 0.18 \mathrm{CPM} / \mathrm{mg}$ tissue $)$ and ipsilateral $(1.52 \pm$ 2.0 $\mathrm{CPM} / \mathrm{mg}$ tissue $)$ or contralateral brain $(0.24 \pm$ $0.15 \mathrm{CPM} / \mathrm{mg}$ tissue).

\section{Intratumoral injection of DTI-015 results in improved tumor to normal tissue ratio when compared to IV injection of $B C N U$}

The initial PK experiments detailed above revealed an enhanced TTR for ${ }^{14} \mathrm{C}$-labeled $\mathrm{BCNU}$ and its metabolites both in terms of Cmax and AUC following intratumoral injection of DTI-015. In order to compare these results to that obtained following the standard IV infusion of BCNU, PK evaluations of ${ }^{14} \mathrm{C}-\mathrm{BCNU}$ were performed both 6 and $72 \mathrm{~h}$ following either direct intratumoral injection of DTI-015 or IV infusion of BCNU (Figure $3 \mathrm{a}$ and $\mathrm{b}$ ). Similar to the results seen in the first experiment IT injection of DTI-015 resulted in increased concentrations of radioactivity in the tumor when compared to all other tissues both within and outside the brain at both the 6 (Figure $3 \mathrm{a}$ ) and 72-h time points (Figure $3 \mathrm{~b}$ ). Intravenous infusion of BCNU, on the other hand, resulted in uniform radioactivity in tumor and non-tumor tissues at both time points (Figures $3 a$ and $b$ ). This difference in delivery of ${ }^{14} \mathrm{C}$-label to the tumor following IT injection of DTI-015 resulted in a $>100-$ fold higher concentration of label within the tumor than that achieved following IV injection of the same quantity of drug at the $6(P=0.065)$ and $72-\mathrm{h}$ $(P<0.015)$ time points. More importantly, although IT injection of ${ }^{14} \mathrm{C}-\mathrm{BCNU}$ did afford an enhanced exposure of tumor to the infused radioactivity it did not significantly alter the exposure of all other tissues when compared to IV injection at both the 6 or $72 \mathrm{~h}$ time points $(P>0.5)$.

The enhancement in exposure of tumors to ${ }^{14} \mathrm{C}$-label as compared to other tissues following IT injection when compared to IV infusion is further seen when the tumor-to-tissue ratios (TTR) at both 6 and $72 \mathrm{~h}$ after administration of drug are examined $(P<0.01)$. The increased concentration of ${ }^{14} \mathrm{C}$-label within the tumor without a corresponding increase in systemic exposure led to TTRs following IT injection of DTI-015 that were all greater than 10-fold with an average TTR of $175 \pm 49$ at 6-h and $97 \pm 23$ at 72-h. Not surprisingly, after IV infusion of BCNU there was no enhancement of delivery to the tumor compared to any other tissues with an average TTR at $6 \mathrm{~h}$ of $1.0 \pm 0.2$ and at $72 \mathrm{~h}$ of $0.66 \pm 0.14$. So, there was no beneficial therapeutic ratio obtained following IV infusion compared to a 100 -fold therapeutic ratio obtained following IT injection of BCNU.

In addition, the enhanced delivery of ${ }^{14} \mathrm{C}-\mathrm{BCNU}$ to tumor is also seen when looking at the residual radioactivity evident in the tissues of interest 72-h after treatment. As was seen for the initial IT experiments, there was significant residual radioactivity in tumors at $72 \mathrm{~h}$ following IT injection $(77.1 \pm 51.4 \mathrm{CPM} / \mathrm{mg}$ tissue) while after IV injection there was minimal residual radioactivity in tumor tissue $(0.89 \pm 0.25 \mathrm{CPM} / \mathrm{mg}$ tissue). Despite the increase in tumor radioactivity at the $72 \mathrm{~h}$ time point following IT treatment there was only minimal radioactivity in all other tissues $(1.4 \pm$ $0.5 \mathrm{CPM} / \mathrm{mg}$ tissue) which was lower than that seen for IV treatment $(2.3 \pm 0.9 \mathrm{CPM} / \mathrm{mg}$ tissue $)$ although this trend approached but did not achieve statistical significance $(P=0.06)$. 

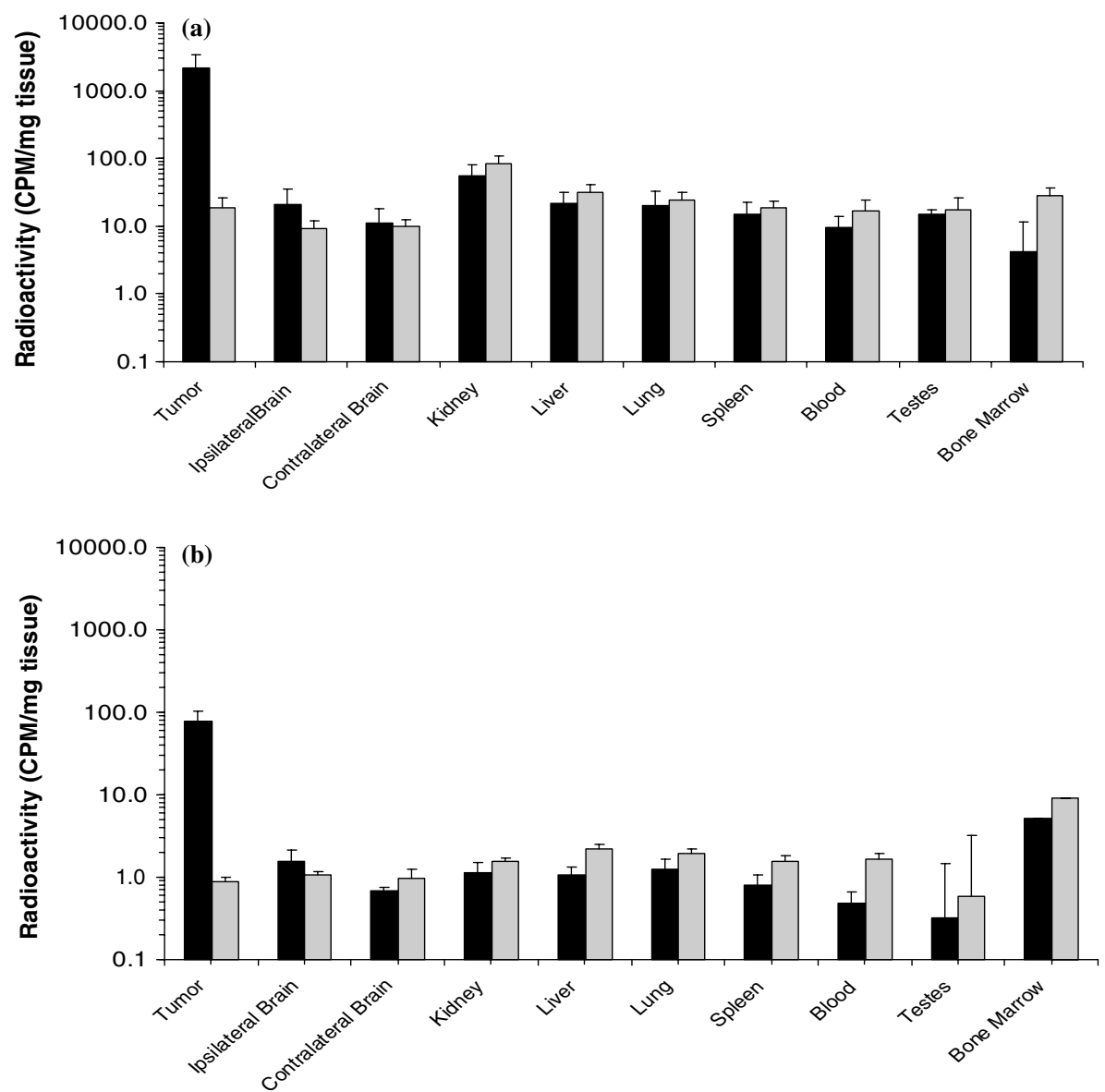

Figure 3. Tissue levels of radioactivity at 6 and $72 \mathrm{~h}$ following administration of ${ }^{14} \mathrm{C}$-labeled DTI-015 IT or BCNU IV. Fischer 344 rats bearing $9 \mathrm{~L}$ gliosarcomas were treated with 1,3-bis(2-chlorethyl-[2- $\left.\left.{ }^{14} \mathrm{C}\right]\right)-1$-nitrosourea via IT injection of DTI-015 $(15 \mu 1100 \% \mathrm{EtOH}, 1 \mathrm{mg}$ cold BCNU, $1 \mu \mathrm{Ci}$ ${ }^{14} \mathrm{C}$-label) or IV infusion of BCNU ( $900 \mu \mathrm{l} 90 \%$ saline $/ 10 \% \mathrm{EtOH}, 1 \mathrm{mg}$ cold BCNU, $1 \mu \mathrm{Ci}{ }^{14} \mathrm{C}$-label). At 6 and $72 \mathrm{~h}$ post-treatment animals were sacrificed and radioactivity was determined in tissues. Data graphed are the mean for 5-6 animals \pm SEM. Background for this experiment was 19 CPM. (a) Radioactivity at $6 \mathrm{~h}$ for DTI-015 IT (black bars) and BCNU IV (gray bars) and (b) Radioactivity at $72 \mathrm{~h}$ for the same groups.

Intratumoral injection of DTI-015 results in an enhanced local volume of distribution compared to injection into normal brain parenchyma

In order to more carefully evaluate both the intra-tumoral and intra-cerebral distribution of BCNU following injection of DTI-015, ${ }^{14} \mathrm{C}$-labeled $\mathrm{BCNU}$ in $15 \mu \mathrm{l}$ ethanol was injected either into established intra-cerebral tumors (4 animals) or into the normal cerebral hemisphere of non-tumor bearing animals (4 animals) which were then sacrificed 1 or $6 \mathrm{~h}$ following injection and whole brains with or without tumor were mounted for sectioning. Representative images of these sections at the $1 \mathrm{~h}$ time point are depicted in Figure 4a. One hour after direct IT injection of ${ }^{14} \mathrm{C}$-BCNU into normal brain there is a very small volume of distribution of the high radioactive signal of $1.5 \pm 0.07 \mu \mathrm{l}$ (mean \pm range) and a relatively high concentration of $\mathrm{BCNU}$ within this volume, $10.6 \pm 2.1 \mathrm{mM}$ (mean $\pm \mathrm{SEM}$ ) (Figure $4 \mathrm{~b}$ ). Of note, this volume is actually smaller than the $15 \mu \mathrm{l}$ volume injected suggesting rapid clearance of the ${ }^{14} \mathrm{C}$ $\mathrm{BCNU}$ from the site of injection within the first $1 \mathrm{~h}$ after injection.

Pathologically at the sight of injection there was a central zone of necrosis surrounded by a peripheral zone of cell degeneration and a small outer zone with pallor consistent with reactive edema. On the fusion images it is apparent that areas of morphology consistent with necrosis or degeneration were limited to the small volume of high radioactive signal. The radioactive signal was largely confined to the site of injection, but in isolated cases there was minimal tracking of the radioactive signal along white matter tracts (i.e. corpus callosum or external capsule) in which case a rim of necrosis or edema was often associated with this tract. In addition, if signal appeared to enter the lateral ventricle there was some associated necrosis of ependymal cells. However, as can be seen in the autoradiographs despite this limited tracking of ${ }^{14} \mathrm{C}-\mathrm{BCNU}$ into adjacent tissues the local volume of distribution was still very small.

In contrast to what was observed in non-tumor bearing normal brain, in the tumor bearing animals there was a large neoplastic mass occupying the prominent portion of one hemisphere (Figure 4a). The average tumor volume for all animals in this experiment was consistent with that from our previous kinetics experiments $(65 \pm 7.5 \mu \mathrm{l})$. Unlike injection of DTI-015 into normal brain, where there was very limited distribution of signal, following direct IT injection of DTI-015 into established 9L tumors there was both a larger volume of 
(a)

H\&E Autoradiography Fusion
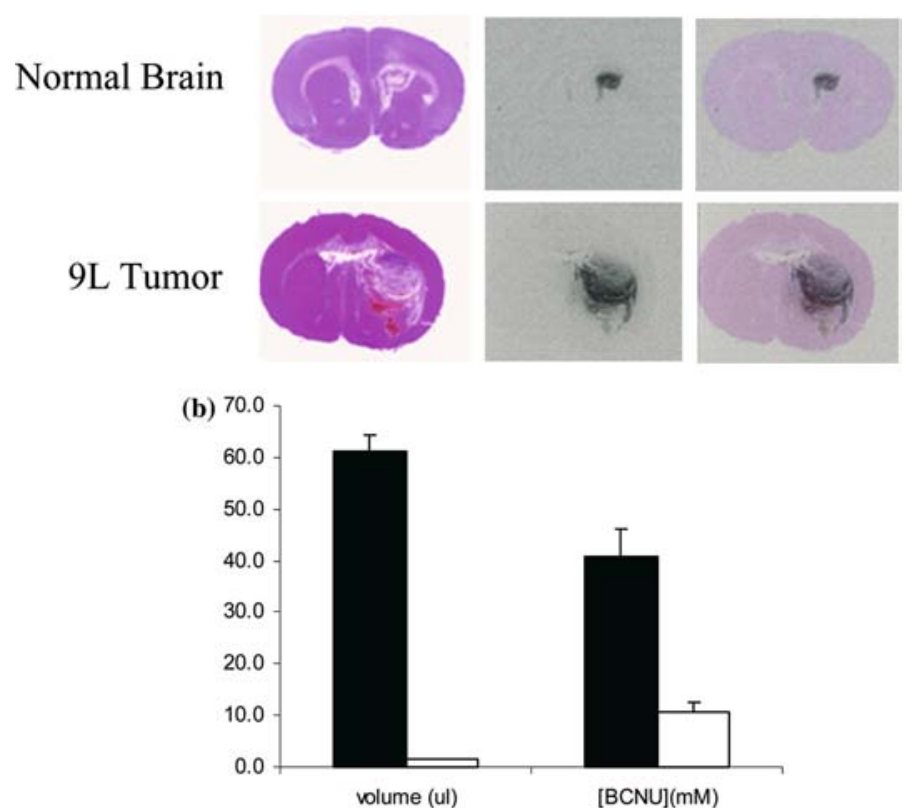

Figure 4. Distribution of radioactive signal following treatment with ${ }^{14} \mathrm{C}$ labeled $\mathrm{BCNU}$ into normal rat brain or intra-cerebral $9 \mathrm{~L}$ tumor. (a) Left column: Hemotoxylin and eosin stained sections of normal brain (top panel) or $9 \mathrm{~L}$ tumors (bottom panel) $1 \mathrm{~h}$ post-IT injection of ${ }^{14} \mathrm{C}-$ [carbonyl]-1,3-bischlorethyl-1-nitrosourea ( $15 \mu \mathrm{l}, 1 \mathrm{mg}$ cold, $0.135 \mu \mathrm{Ci}$ ) in 100\% ethanol. Middle column: Quantitative autoradiographs of the same tissue sections. Right column: Fusion of H\&E and autoradiographic images. (b) A bar plot of the local volume of distribution in $\mu 1$ (average \pm range) and concentration of BCNU in $\mathrm{mM}$ (average \pm SEM) at $1 \mathrm{~h}$ after injection of DTI-015 into 9L tumors (black bars) or normal brain (white bars).

high radioactive signal $61.1 \pm 3.2 \mu$ l (mean \pm range) and a higher concentration of BCNU within this region, $40.9 \pm 5.3 \mathrm{mM}$ (mean $\pm \mathrm{SEM}$ ) (Figure $4 \mathrm{a}$ and $\mathrm{b}$ ). This represents a 38 -fold increase in the local volume of distribution and a 3.8 -fold increase in the concentration of BCNU delivered to this volume.

Pathologically, the high signal areas within the 9L tumor were associated with regions of significant cellular necrosis. There was minimal tracking of high radioactive signal outside of the tumor volume, but in some animals (as in the non-tumor bearing specimens) radiolabel did enter the lateral ventricle with associated necrosis of ependymal cells. In addition, as seen in the overlaid images the high-signal volume for ${ }^{14} \mathrm{C}$-labeled BCNU following intratumoral injection of DTI-015 closely approximated the volume of tumor (even into areas of the tumor which were not completely spherical but had a more invasive component) providing evidence for enhanced delivery of drug not only in the small volume where the drug was initially injected but also throughout the mass of the tumor. In fact, the high concentration volume of radioactive signal at one hour represented $93.9 \pm 4.9 \%$ of the total tumor volume.

A similar trend in terms of enhanced local volume of distribution and increased concentration of BCNU delivered was noted when identical evaluations were performed at $6 \mathrm{~h}$ after injection of DTI-015 into tumor or normal brain (data not shown), but the magnitude of the difference was smaller at this later time point consistent with the clearance of BCNU from tissues during the first $6 \mathrm{~h}$ (as documented in Figure 2 and Table 1).
Injection of DTI-015 or ethanol in to established 9L tumors results in a decrease in tumor blood flow

The PK and autoradiographic data presented above suggested a substantial difference between the delivery of ${ }^{14} \mathrm{C}-\mathrm{BCNU}$ to tumor and both adjacent and contralateral brain. In an attempt to explain this phenomena, the impact of intratumoral injection of DTI-105, ethanol, or sham injection on tumor perfusion was evaluated using MRI-based techniques. In the first set of experiments animals were administered gadolinium DTPA (GdDTPA) contrast intraperitoneally and then imaged 20,80 and $110 \mathrm{~min}$ following injection of contrast. These scans (Figure 5a) revealed a brisk rise in GdDTPA uptake within the tumor which is highest at the 20-min time point with a much smaller signal at $80 \mathrm{~min}$ and only trace contrast enhancement at $110 \mathrm{~min}$ after administration of contrast. If the same animal is treated by sham insertion of needle into the tumor $20 \mathrm{~min}$ after the administration of contrast there is no significant change in the level or dynamics of contrast enhancement (data not shown). However, in animals treated with contrast followed by IT ethanol (Figure 5b) or DTI-015 (Figure 5c) there was increased contrast enhancement identified at both the 80 and 110-min scan. In addition, not only were there areas of increased enhancement there were also other areas within the ethanol or DTI-015 injected tumors with significantly decreased contrast enhancement (which appear as black voids on the images in $5 \mathrm{~b}$ and $5 \mathrm{c}$ ) perhaps do to the inability of GdDTPA to enter into regional volumes of the tumor where high concentrations of ethanol were 

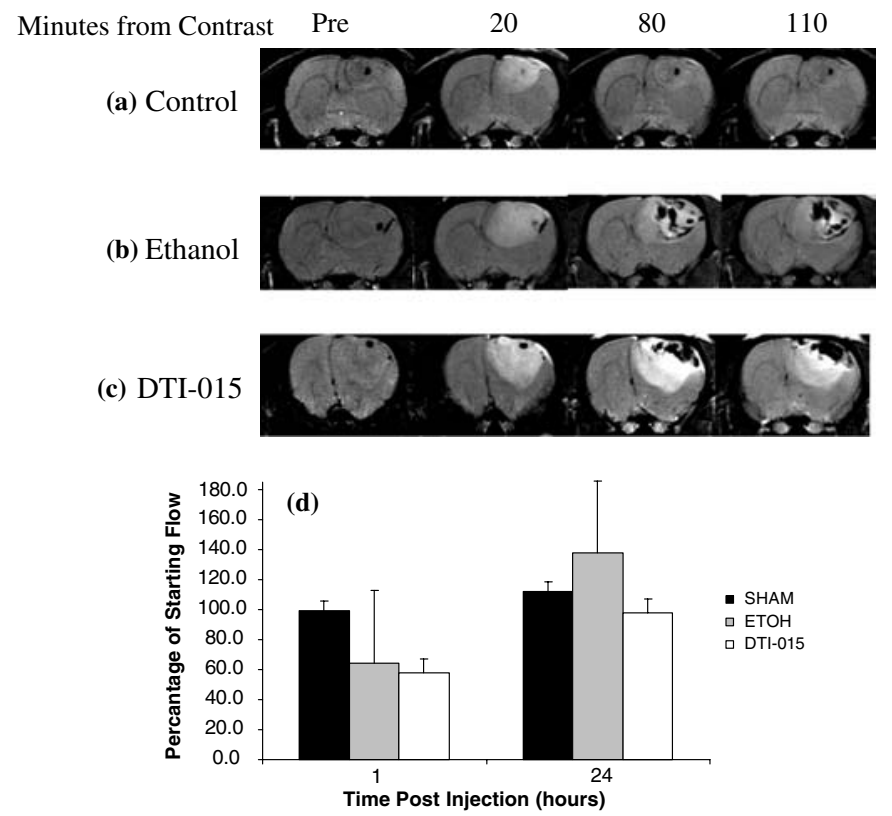

Figure 5. Dynamic contrast imaging and tumor blood flow following Ethanol or DTI-015 treatment of 9L tumors. T1-weighted MR images of 9L tumors either before (pre-) or 20, 80, or 110 min following IP administration of GdDTPA. Treatment was performed after the 20 min scan and consisted of no treatment (control, a), or injection of $15 \mu$ l ethanol (b), or DTI-015 (c). In Figure 6d, quantitative perfusion imaging of 9L tumors was performed before and both 1 and $24 \mathrm{~h}$ after the same three treatments. Blood flow in tumors as a percentage of baseline blood flow is plotted for the average \pm SEM of 3 animals for: Sham (black bars), ethanol (gray bars), or DTI-015 (white bars).

present. In addition, when the reverse experiment was performed where DTI-015 or ethanol were administered 20 min prior to contrast there was a corresponding decrease in contrast uptake within the tumor as compared to animals only treated with sham insertion of the needle into the tumor again suggesting that DTI-015 or ethanol treatment decreased tumor perfusion as demonstrated by alterations in dynamic contrast enhancement (data not shown).

To further evaluate this alteration in tumor perfusion, quantitative perfusion imaging [33] was used in intracerebral 9L tumors prior to and both 1 and $24 \mathrm{~h}$ after: sham, ethanol, or DTI-015 injection IT (Figure 5d). Prior to treatment the tumors from the 3 different groups had similar baseline blood flow (average $45.4 \pm 5.6 \mathrm{ml} / 100 \mathrm{~g} / \mathrm{min}, P<0.91)$. Sham treatment caused no significant change in blood flow at either the 1 or 24 -h time points $(99.2 \pm 6.6 \%$ and $112.2 \pm 9.3 \%)$. In contrast, in tumors treated with IT injection of DTI015 there was a significant decrease in tumor perfusion at the one hour post injection time point $(57.7 \pm 6.0 \%$, $P=0.018$ ) which had largely normalized at the $24 \mathrm{~h}$ and later time points $(97.6 \pm 10.0 \%, P=0.39)$. In ethanol treated animals there was a trend toward decreased blood flow at one hour $(64.6 \pm 47.9 \%)$ that did not achieve statistical significance $(P=0.88)$. Therefore, alterations in tumor perfusion following injection of DTI-015 confirm the results seen in dynamic contrast images that DTI-015 administered IT caused a transient local decrease in tumor blood flow.

Systemic pharmacokinetics of $B C N U$ in patients treated with DTI-015

The rat $\mathrm{PK}$ data suggested both an increase in ${ }^{14} \mathrm{C}$-BCNU delivery to tumor and a markedly enhanced
TTR ratio for ${ }^{14} \mathrm{C}$-BCNU administered by IT injection as compared to IV infusion. In order to perform an initial evaluation of systemic exposure to BCNU following treatment with DTI-015 three patients treated on a prospective clinical protocol for recurrent high-grade glioma (20) had blood levels of BCNU determined at serial time points after injection of DTI-015. Following treatment with DTI-015 the Cmax in the blood $(93.6 \pm 49.3 \mathrm{ng} / \mathrm{ml})$ was observed approximately $1 \mathrm{~h}$ following injection (53 $\pm 14 \mathrm{~min}$, Figures $6 \mathrm{a}$ and $\mathrm{b}$ ). This peak blood concentration of BCNU occurred both later and was lower than that previously observed following IV administration of BCNU to patients where a peak concentration of $2000 \mathrm{ng} / \mathrm{ml}$ was observed at 40 min following the start of a $30-\mathrm{min}$ IV infusion (i.e. $10 \mathrm{~min}$ after the completion of treatment) [27]. This enhanced therapeutic index is further highlighted by the fact that for patients being treated with DTI-015 the average injected mass of BCNU (3.98 \pm 0.76 $\mathrm{mg} / \mathrm{kg}$ ) was 2-fold higher than that utilized for IV infusion $(1.71 \pm 0.11 \mathrm{mg} / \mathrm{kg})$. Finally, despite the altered route of administration the terminal clearance of BCNU from the systemic circulation was similar in both cases with the half-life observed for all time points $>45$ min of $106 \pm 14$ min for DTI-015 administration and 95 min for IV treatment.

\section{Discussion}

The experiments reported here reveal both the local and systemic distribution of ${ }^{14} \mathrm{C}$-label following IT delivery of ${ }^{14} \mathrm{C}-\mathrm{BCNU}$ in the rat $9 \mathrm{~L}$ gliosarcoma model. As indicated there was a $>100$-fold increase in the amount of radioactivity delivered to tumor tissue 

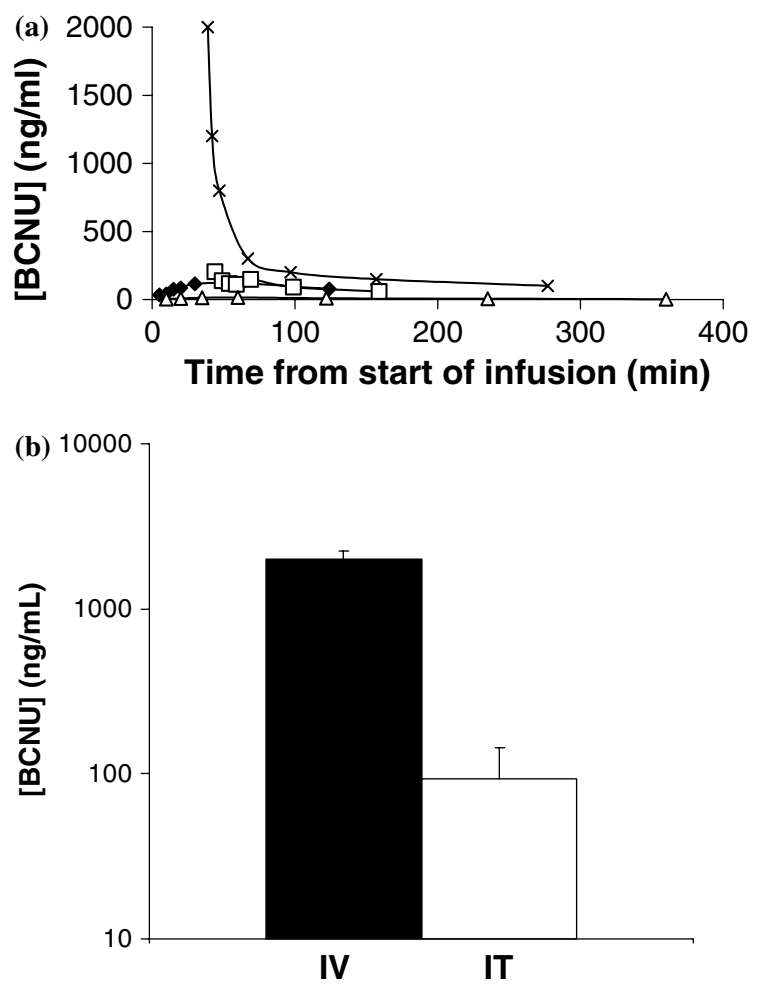

Figure 6. Systemic pharmacokinetics of BCNU in humans following IV infusion of BCNU or IT delivery of DTI-015. (a) The concentration of BCNU in peripheral blood $(\mathrm{ng} / \mathrm{ml})$ as a function of time after start of infusion (minutes) is plotted for 3 patients treated with DTI-015 (open square, open triangle, and closed diamond) or for the average of 4 patients treated by IV infusion (x-symbols). Data for IT represent the actual values at each time point and that for IV the mean \pm SEM taken from Cancer Treat Rep, 62: 1305-1312, (1978). (b) Peak concentration of $\mathrm{BCNU}$ in serum for the above patients.

following DTI-015; in addition, despite the increased delivery of drug to tumor via IT injection there was no appreciable increase in the systemic exposure to ${ }^{14} \mathrm{C}$ BCNU or its metabolites compared to IV treatment. The dose of $1 \mathrm{mg}$ of BCNU utilized by either route in this study corresponds to $6.6-8.0 \mathrm{mg} / \mathrm{kg}$ which is similar to the $\frac{1}{2}$ LD10 dose previously reported $(6.65 \mathrm{mg} / \mathrm{kg})$, where LD10 equals the dose that caused death due to drug toxicity in $10 \%$ of the animals [28]. In previous reports, treatment with the $\frac{1}{2}$ LD10 dose systemically caused a small cytotoxic effect in this 9L gliosarcoma model (0.2 log cell-kill), a modest change in apparent cellular water diffusion, no appreciable increase in animal survival, and no systemic toxicity $[28,29]$. Therefore, these kinetic data suggest that the in the $9 \mathrm{~L}$ intracerebral rat model the use of DTI-015 at the dose of $1 \mathrm{mg}$ provides at least a 100 -fold increase in tumor exposure to BCNU compared to IV administration while providing a systemic exposure that has been documented to be well tolerated with minimal toxicity.

In addition, the enhanced delivery of ${ }^{14} \mathrm{C}-\mathrm{BCNU}$ to tumor compared to systemic tissues following treatment with DTI-015 is similar to what was previously observed by measuring DNA adducts in RIF-1 flank tumors grown in nude mice following either IP infusion of BCNU or IT injection of DTI-015 where there was a 164-fold increase in the DNA adducts identified in the tumor after treatment with DTI-015 as compared to IP infusion. In addition, despite the increased delivery of BCNU to flank tumors, the level of adducts in other systemic tissues (brain, lung, liver, and kidney) were not increased above background following IT treatment with DTI-015 [30].

The enhancement in the tumor exposure to ${ }^{14} \mathrm{C}$ BCNU and its metabolites following injection of DTI015 likely explains the therapeutic advantage previously reported for rats bearing 9L gliosarcoma treated with DTI-015 [23]. In that study rats received a volume of DTI-015 up to $50 \%$ of the tumor volume or $30 \mu \mathrm{l}$, whichever was smaller, containing up to $2 \mathrm{mg}$ of BCNU. This treatment regimen was based on that previously reported in the phase I/II trial of DTI-015 in patients with recurrent high-grade glioma [20]. That study escalated the volume of ethanol and the dose of BCNU utilized in parallel to achieve the maximum values for these two parameters. The MTD was eventually established as $50 \%$ of the tumor volume up to $5 \mathrm{ml}$ and $240 \mathrm{mg}$ BCNU. Therefore, when performing studies to evaluate MRI based measures of early therapeutic efficacy [23] similar parameters were utilized for the rat glioma model.

Treatment with these parameters in the 9L glioma model resulted in massive cell death (as documented by diffusion weighted MRI), complete radiographic regression of tumor by 16 days post injection, and $75 \%$ of animals tumor free at 30 days after treatment. This is significantly better than that previously observed using systemic administration of a much higher dose of BCNU $(2 \times$ LD10 BCNU or 3.3-4.0 mg) where only minimal tumor regression with no complete responses was observed and all animals still succumbed to tumor related death within 20 days of treatment [22,29]. Taken together these sets of data suggest that IT injection of DTI-015 results in a dramatic increase in tumor response to treatment compared to systemic infusion even for a smaller dose of drug delivered IT. Further, the current PK data which reveal a greater than 100-fold increase in delivery of ${ }^{14} \mathrm{C}$-BCNU to tumors by IT treatment compared to IV infusion represent a viable explanation of the enhanced efficacy observed in this preclinical model of high-grade glioma.

Clinically diffuse fibrillary high-grade gliomas are known for the invasive nature of the disease with tumor cells often found on pathologic review as much as many centimeters from the site of the tumor within what grossly appears to be normal brain tissue [1]. It is unclear how the result obtained using the 9L gliosarcoma model, where intracerebral tumors tend to grow as a contained mass with little invasion in to the surrounding brain tissue, can be extrapolated to invasive nature of primary high-grade brain tumors. To date, a preclinical model of DTI-015 in an infiltrative tumor model has not yet been reported to ascertain whether or not administration of DTI-015 will result in enhanced delivery of BCNU to infiltrating tumor cells. However, the local distribution of ${ }^{14} \mathrm{C}$-BCNU in tumors observed in the present study following direct IT injection of DTI-015 would suggest transit of drug throughout the tumor. In fact, some of the non-uniform tendrils of $9 \mathrm{~L}$ tumor 
appeared to have significant tracking of radioactive BCNU suggesting that following injection of DTI-015 the drug was not simply expanding to fill a spherical volume, but it was in fact being transported preferentially in tumor tissue as compared to surrounding normal brain. Indeed approximately $90 \%$ of the tumor appeared to harbor the highest signal intensity of BCNU which correlated with a concentration of $40.9 \pm$ $5.2 \mathrm{mM}$. This is much higher ( $>300$-fold) than the $\mathrm{IC}_{95}$ $(100 \mu \mathrm{M})$ observed in culture for BCNU in the 9L cells used in this study (D.A.H., unpublished data).

The local PK data in this animal model also confirm the previous report of a patient with recurrent GBM treated with DTI-015 (240 mg in $4 \mathrm{ml}$ ) where $60 \mathrm{~min}$ after treatment stereotactic biopsies were performed and measurement of DNA adducts revealed an 879-fold increase above background in tumor tissue up to $0.9 \mathrm{~cm}$ from the site of injection and a 6-fold increase above background for tissue even up to $2.4 \mathrm{~cm}$ from injection [31]. The combination of enhanced local concentrations of drug and increased delivery of drug to surrounding brain may explain the quite positive result observed in the phase I/II trial where patients with recurrent inoperable GBM still achieved a median survival of 55 weeks, which is comparable to that for most patients at the time of diagnosis, and was considerably better than matched historical controls at the same treating institution where the median survival of recurrent and unresectable patients was only 25 weeks [20].

Therefore, both preclinical and clinical data suggest that solvent facilitated perfusion enhances delivery of BCNU to tumors following IT injection. However, the mechanism by which ethanol facilitates the transit of BCNU throughout the tumor has not been fully elucidated. It does appear to be a factor of the organic solvent, for treatment of Walker 256 flank tumors with direct injection of $\mathrm{BCNU}$ in either $100 \%$ ethanol or $10 \%$ ethanol $/ 90 \%$ saline gave markedly different antitumor response even for the same dose of BCNU [32]. A number of hypotheses can be made as to the mechanism of the preferential delivery of ${ }^{14} \mathrm{C}$-BCNU to the tumor following IT treatment with DTI-015.

First, 9L tumors have been documented to have a higher cellular density and choline : ethanoloamine ratio than surrounding normal rat brain suggesting a more lipophilic cellular mass [33]. Ethanol may, therefore, facilitate partitioning of BCNU into this lipophilic tumor better than BCNU in water, and this enhanced partitioning may be greater in tumor than in normal brain which is not as lipophilic. Transit of BCNU may, thus, be facilitated in this fashion within the tumor until the solvent interface reaches normal brain tissue at which time there is less of an advantage for the organic solvent and decreased movement of the drug into surrounding brain parenchyma.

A second possible contributing factor is the documented fact that 9L tumors have lower blood flow than normal surrounding brain $[34,35]$ which by our measurements was $45.4(\mathrm{ml} / 100 \mathrm{mg}$ tissue/min) in tumor vs. $138 \pm 25(\mathrm{ml} / \mathrm{mg}$ tissue $/ \mathrm{min})$ in the brain surrounding the tumor [36]. As a result of this decreased blood flow within the tumor the injected BCNU would have lower clearance in tumor as compared to normal surrounding brain allowing a greater chance for the drug to diffuse throughout the tumor. Similarly, once the drug does diffuse out of the tumor into normal brain tissue the greater perfusion of these tissues would result in enhanced clearance, and, therefore, lower residual concentrations of $\mathrm{BCNU}$ in brain tissue.

A third option, which is in part supported by our perfusion and dynamic contrast images, is that either $\mathrm{BCNU}$, ethanol, or the combination may alter the blood flow within the tumor thus further enhancing the retention of the drug within the tumor as compared to surrounding tissues. One possible mechanism to explain these different responses in perfusion to DTI-015 treatment is that the aberrant blood vessels which develop within the tumor via neoangiogenic processes may be more susceptible to this alteration in blood flow following injection of DTI-015 than mature vessels found within the surrounding brain parenchyma. Finally, it is also may be that each of these three theories and perhaps other undetermined factors all contribute to both the increased local volume of delivery of BCNU to tumors and the enhanced TTR observed following administration of DTI-015.

Finally, preliminary data are presented on the systemic exposure of patients to BCNU following IT injection of DTI-015 and are compared to previously published results for IV infusion of BCNU. Despite a 2 -fold increase in the amount of administered BCNU, in the patients tested DTI-015 resulted in a 20-fold decrease in the Cmax for $\mathrm{BCNU}$ in the peripheral blood. Despite this decreased Cmax there was no apparent difference in the clearance of BCNU from the systemic circulation as determined by the terminal halflife. It is interesting to note that the human data revealed a 20 -fold decrease in the systemic BCNU exposure between these two modes of administration while the rat PK data reported similar overall systemic exposure. One potential explanation for this difference is that the human clinical data measured absolute BCNU levels, while the rat $\mathrm{PK}$ data recorded ${ }^{14} \mathrm{C}$ radioactivity. Therefore, much of the late radioactivity seen in the rat model my represent inactive metabolites or terminal adducts of $\mathrm{BCNU}$ and not the native compound.

\section{Conclusion}

The use of DTI-015 offers a 100-fold or greater increase in the delivery of ${ }^{14} \mathrm{C}$ label to intra-cerebral $9 \mathrm{~L}$ tumor compared to IV administration without any increase in the systemic exposure. Further, injection of ${ }^{14} \mathrm{C}$-BCNU in ethanol appears to provide rapid and near complete saturation of tumors by BCNU with little deposition of drug into surrounding tissues, which may be in part due to alterations in tumor blood flow following injection of DTI-015. Finally, in patients treated with DTI-015 as compared to IV infusion of BNCU there is: a delay in the time to achieve Cmax, a decrease in systemic exposure to 
BCNU, but a similar terminal elimination rate for BCNU. All of these preclinical and clinical data suggest that DTI-015 warrants further investigation as a means to provide enhanced tumor specific delivery of BCNU to patients with high-grade glioma.

\section{Acknowledgements}

Support for this work was provided by NIH Grants: P01CA85878, P50CA01014, and R24CA83099 and by an institutional grant from Direct Therapeutics Inc. to B.D.R. D.A.H. had support from a Varian Medical Systems/RSNA Holman Pathway Research Resident Seed Grant.

\section{References}

1. Behin A, Hoang-Xuan K, Carpentier AF, Delattre JY: Primary brain tumours in adults. Lancet 361: 323-331, 2003

2. Dorr R, Hoff D: Carmustine. In: Dorr R, and Hoffs D (eds) Cancer Chemotherapy Handbook. Appleton and Lange, Norwalk, 1994, pp. 267-275

3. Stewart LA: Chemotherapy in adult high-grade glioma: a systematic review and meta- analysis of individual patient data from 12 randomised trials. Lancet 359: 1011-1018, 2002

4. Hasleton PS, O'Driscoll BR, Lynch P, Webster A, Kalra SJ, Gattamaneini HR, Woodcock AA, Poulter LW: Late BCNU lung: a light and ultrastructural study on the delayed effect of BCNU on the lung parenchyma. J Pathol 164: 31-36, 1991

5. O'Driscoll BR, Hasleton PS, Taylor PM, Poulter LW, Gattameneni HR, Woodcock AA: Active lung fibrosis up to 17 years after chemotherapy with carmustine (BCNU) in childhood. $\mathrm{N}$ Engl J Med 323: 378-382, 1990

6. Thompson GR, Larson RE: The hepatotoxicity of 1,3-bis (2chloroethyl)-1-nitrosurea (BCNU) in rats. J Pharmacol Exp Ther 166: 104-112, 1969

7. Hochberg FH, Pruitt AA, Beck DO, DeBrun G, Davis K: The rationale and methodology for intra-arterial chemotherapy with BCNU as treatment for glioblastoma. J Neurosurg 63: 876-880, 1985

8. Hassenbusch SJ, Anderson JH, Whiting DM: Intra-arterial chemotherapy for brain tumors. Cleve Clin J Med 57: 513-520, 1990

9. Walter KA, Tamargo RJ, Olivi A, Burger PC, Brem H: Intratumoral chemotherapy. Neurosurgery 37: 1128-1145, 1995

10. Brem H, Piantadosi S, Burger PC, Walker M, Selker R, Vick NA, Black K, Sisti M, Brem S, Mohr G, et al.: Placebocontrolled trial of safety and efficacy of intraoperative controlled delivery by biodegradable polymers of chemotherapy for recurrent gliomas. The Polymer-brain Tumor Treatment Group. Lancet 345: 1008-1012, 1995

11. Kleinschmidt-DeMasters BK: Intracarotid BCNU leukoencephalopathy. Cancer 57: 1276-1280, 1986

12. Miller DF, Bay JW, Lederman RJ, Purvis JD, Rogers LR, Tomsak RL: Ocular and orbital toxicity following intracarotid injection of BCNU (carmustine) and cisplatinum for malignant gliomas. Ophthalmology 92: 402-406, 1985

13. Westphal M, Hilt DC, Bortey E, Delavault P, Olivares R, Warnke PC, Whittle IR, Jaaskelainen J, Ram Z: A phase 3 trial of local chemotherapy with biodegradable carmustine (BCNU) wafers (Gliadel wafers) in patients with primary malignant glioma. Neuro-oncol 5: 79-88, 2003

14. Olivi A, Grossman SA, Tatter S, Barker F, Judy K, Olsen J, Bruce J, Hilt D, Fisher J, Piantadosi S: Dose escalation of carmustine in surgically implanted polymers in patients with recurrent malignant glioma: a new approaches to brain tumor therapy CNS consortium trial. J Clin Oncol 21: 1845-1849, 2003

15. Fleming AB, Saltzman WM: Pharmacokinetics of the carmustine implant. Clin Pharmacokinet 41: 403-419, 2002

16. Bobo RH, Laske DW, Akbasak A, Morrison PF, Dedrick RL, Oldfield EH: Convection-enhanced delivery of macromolecules in the brain. Proc Natl Acad Sci USA, 91: 2076-2080, 1994

17. Vavra M, Ali MJ, Kang EW, Navalitloha Y, Ebert A, Allen CV, Groothuis DR: Comparative pharmacokinetics of 14C-sucrose in RG-2 rat gliomas after intravenous and convection-enhanced delivery. Neuro-oncol 6: 104-112, 2004

18. Bruce JN, Falavigna A, Johnson JP, Hall JS, Birch BD, Yoon JT, Wu EX, Fine RL, Parsa AT: Intracerebral clysis in a rat glioma model. Neurosurgery, 46: 683-691, 2000

19. Mardor Y, Roth Y, Lidar Z, Jonas T, Pfeffer R, Maier SE, Faibel M, Nass D, Hadani M, Orenstein A, Cohen JS, Ram Z: Monitoring response to convection-enhanced taxol delivery in brain tumor patients using diffusion-weighted magnetic resonance imaging. Cancer Res 61: 4971-4973, 2001

20. Hassenbusch SJ, Nardone EM, Levin VA, Leeds N, Pietronigro D: Stereotactic injection of DTI-015 into recurrent malignant gliomas: phase I/II trial. Neoplasia 5: 9-16, 2003

21. Pietronigro D, Drnovsky F, Cravioto H, Ransohoff J: DTI-015 produces cures in T9 gliosarcoma. Neoplasia 5: 17-22, 2003

22. Chenevert TL, McKeever PE, Ross BD: Monitoring early response of experimental brain tumors to therapy using diffusion magnetic resonance imaging. Clin Cancer Res 3: 1457-1466, 1997

23. Hall DE, Moffat BA, Stojanovska J, Johnson TD, Li Z, Hamstra DA, Rehemtulla A, Chenevert TL, Carter J, Pietronnigro D, Ross BD: Therapeutic Efficacy of DTI-015 using diffusion MRI as an early surrogate marker. Clin Cancer Res 10: 7852-7859, 2004

24. Ross BD, Merkle H, Hendrich K, Staewen RS, Garwood M: Spatially localized in vivo $1 \mathrm{H}$ magnetic resonance spectroscopy of an intracerebral rat glioma. Magn Reson Med 23: 96-108, 1992

25. Colvin M, Brundrett RB, Cowens W, Jardine I, Ludlum DB: A chemical basis for the antitumor activity of chloroethylnitrosoureas. Biochem Pharmacol 25: 695-699, 1976

26. DeVita VT, Denham C, Davidson JD, Oliverio VT: The physiological disposition of the carcinostatic 1,3-bis(2-chloroethyl)-1-nitrosourea (BCNU) in man and animals. Clin Pharmacol Ther 8: 566-577, 1967

27. Levin VA, Hoffman W, Weinkam RJ: Pharmacokinetics of BCNU in man: a preliminary study of 20 patients. Cancer Treat Rep 62: 1305-1312, 1978

28. Ross BD, Zhao YJ, Neal ER, Stegman LD, Ercolani M, BenYoseph O, Chenevert TL: Contributions of cell kill and posttreatment tumor growth rates to the repopulation of intracerebral 9L tumors after chemotherapy: an MRI study. Proc Natl Acad Sci USA, 95: 7012-7017, 1998

29. Chenevert TL, Stegman LD, Taylor JM, Robertson PL, Greenberg HS, Rehemtulla A, Ross BD: Diffusion magnetic resonance imaging: an early surrogate marker of therapeutic efficacy in brain tumors. J Natl Cancer Inst 92: 2029-2036, 2000

30. Bodell WJ, Giannini DD, Singh S, Pietronigro D, Levin VA: Formation of DNA adducts and tumor growth delay following intratumoral administration of DTI-015. J Neurooncol 62: 251258, 2003

31. Bodell WJ, Giannini DD, Hassenbusch S, Levin VA: Levels of N7-(2-hydroxyethyl)guanine as a molecular dosimeter of drug delivery to human brain tumors. Neuro-oncol 3: 241-245, 2001

32. Simpson-Herren L, Pietronigro D: Intratumoral injection of DTI015 in the Walker 256 subcutaneous model. Proc Am Assoc Cancer Res 1999, 583 pp.

33. Ross BD, Chenevert TL, Kim B, Ben-Yoseph O: Magnetic resonance imaging and spectroscopy: application to experimental neuro-oncology. Q Magn Reson Biol Med 1: 89-106, 1994

34. Fross RD, Warnke PC, Groothuis DR: Blood flow and blood-totissue transport in 9L gliosarcomas: the role of the brain tumor model in drug delivery research. J Neurooncol 11: 185-197, 1991

35. Steen RG, Graham MM: $31 \mathrm{P}$ magnetic resonance spectroscopy is sensitive to tumor hypoxia: perfusion and oxygenation of rat $9 \mathrm{~L}$ 
gliosarcoma after treatment with BCNU. NMR Biomed 4: 117-124, 1991

36. Moffat B, Chenevert T, Hall D, Rehemtulla A, Ross B: Quantitative perfusion imaging by continuous inversion using pulse trained arterial spin labeling. J Magn Reson Imaging, in press
Address for offprints: Brian D. Ross, Ph.D., The Center for Molecular Imaging, The University of Michigan Medical Center, 9403 MSRB III, 1500 East Medical Center Drive, Ann Arbor, MI 48109-0648, USA; Tel.: +1-734-763-2099; Fax: +1-734-647-2563; E-mail: bdross@ umich.edu 